\title{
Investigation Of Levels Of Luteinizing Hormone And Follicular Stimulating Hormone Among Women With Polycystic Ovary Syndrome In Abakaliki, Nigeria
}

\author{
Oti-wilberforce R.O ${ }^{1}$, Onyeanusi, J.C. ${ }^{1}$, Nworie A., ${ }^{1}$ Oti Wilberforce J.O ${ }^{2}$ \\ ${ }^{I}$ Department of Medical Laboratory Science, Ebonyi State University, Abakaliki, Ebonyi State, Nigeria. \\ ${ }^{2}$ Department of Industrial Chemistry, Ebonyi State University, Abakaliki, Ebonyi State, Nigeria.
}

\begin{abstract}
Sixty samples of blood were collected from women who attended fertility clinic were collected from January to August 2015 and they were analyzed for fertility hormone such as luteinizing Hormone (LH) and Follicular Stimulating Hormone (FSH) using standard methods. Thirty of the samples were collected from women with polycystic ovary syndrome (PCOS) while the remaining thirty samples serve as control. The results obtained from women with PCOS revealed mean values of luteinizing Hormone $(\mathrm{LH})$ and Follicular Stimulating Hormone as $22.58 \pm 2.781 \mathrm{miu} / \mathrm{ml}$ and $8.570 \pm 1.149 \mathrm{miu} / \mathrm{ml}$; respectively while the control were $9.080 \pm 0.720$ $\mathrm{miu} / \mathrm{ml}$ and $5.643 \pm 0.720 \mathrm{miu} / \mathrm{ml}$ respectively. From the results, levels of LH were higher than FSH and the values obtained from the PCOS group were significantly higher than those of control. The statistical analysis showed that the variation in the parameters determined were statistically significant $(p<0.05)$ as determined by one way analysis of variance. This shows that elevation in fertility hormones do occur in Polycystic Ovary Syndrome.
\end{abstract}

Keywords: Luteinizing Hormone, Follicular Stimulating Hormone, Women, Polycystic and Ovary

\section{Introduction}

Polycystic ovary syndrome (PCOS), also known as hyper androgenic anovulation (HA) is a set of symptoms resulting from hormonal imbalance in women [1]. PCOS occurs when a woman does not undergo her monthly ovulation, which apparently is caused by an interruption in the secretion of hormones which consequently disrupts the interrelationship connecting the ovaries, brain and hormones.Some of the symptoms that characterize PCOS include visible and excessive facial and body hairs, lack of menstruation or irregular menstrual periods, pelvic pain, acne, difficulty in getting pregnant, in addition to patches of thick, darker, velvety skin [2]. Moreover PCOS is often associated with heart disease, obesity, type 2 diabetes, mood disorders, obstructive sleep apnea, , and endometrial cancer [3]. Lutenizing Hormone (LH) and Follicle Stimulating Hormone synergize during PCOS condition and they are produced by gonadotropic cells in pituitary gland of the brain. They play cardinal roles in puberty menstruation and fertility. Active rise of LH is known to triggers off ovulation. Lutenizing hormone and Follicle-stimulating hormone are the hormones that encourage ovulation [4]. At the beginning of the cycle, LH and FSH levels usually range between about $5-20 \mathrm{ml} / \mathrm{ml}$. Most women have about equal amounts of LH and FSH during the early part of their cycle. However, there is a surge of LH in which the amount of LH increases to about $25-40 \mathrm{mlU} / \mathrm{ml} 24$ hours before ovulation occurs. Once the egg is released by the ovary, the LH level goes back down. While many women with PCOS still have LH and FSH values within the 5-20 $\mathrm{mlU} / \mathrm{ml}$ range, their LH level is often twice or thrice that of the FSH level. For example, it is typical for women with PCOS to have an LH level of about $18 \mathrm{mlU} / \mathrm{ml}$ and a FSH level of about $6 \mathrm{mlU} / \mathrm{ml}$ (note that both levels fall within the normal range of 5-20 mlU/ml). This situation is known as an elevated LH to FSH ratio it is of 3:1 ratio. This change in the LH to FSH ratio is enough to disrupt ovulation. While this used to consider an important aspect in diagnosing PCOS, it is now considered less useful in diagnosing PCOS, but is still helpful when looking at the overall picture [5].

Globally there is an astronomical increase in cases of PCOS which invariably has resulted to increased cases of infertility in women. Statistically one in every fifteen women in the world suffers from PCOS [6]. Higher cases of PCOS were observed in Middle East and western Africa. According to Right Diagnosis (2015) in Statistic by Country for Polycystic Ovary Syndrome, the current statistics of PCOS in Nigeria shows established cases of 443,758. In Nigeria, especially in South East, there are prevalent cases of PCOS, precisely one in every six infertile Nigerian woman [7]. Polycystic ovarian syndrome has been discovered to be one of the major causes of infertility among women of child bearing age. This is due to its adverse effect on the female fertility hormones. Infertility is one of the reasons for failed marriages as reproduction is one of the goals of marriage. This project investigates the levels of the LH and FSH hormones on women with polycystic ovarian syndrome in Abakaliki. This work also provides vital baseline data for further PCOS researches in Ebonyi State, Nigeria. 


\section{Sample Collection}

\section{Materials And Methods}

Samples were collected from patients who attended gynecology specialty clinic at Federal Teaching Hospital (FETHA). Ethical clearance was obtained from FETHA Ethical committee after which $5 \mathrm{mls}$ of blood were collected from each of the women involved in the study following the approved protocol. Neat puncture was made at the vein to avoid haemolysis and air embolism. The blood samples were collected in a plain tube and were allowed to clot and retract before centrifuging at 3000rpm. The serum was separated from the red cells and was used to carry out the test. Care was taken to avoid mixing red cells in the serum.

\section{Determination Leutinizing Hormone (LH)}

Level of LH was determined using Enzyme Immunoassay Test Kit produce by Biochek, Inc. for the quantitative determination of Leutinizing Hormone ( $\mathrm{LH})$ concentration in human serum. The LH Quantitative Test is based on a solid phase enzyme-linked immunosorbent assay (ELISA). THE assay system utilizes a mouse monoclonal anti-a-LH antibody for solid phase (microtiter wells) immobilization and a mouse monoclonal anti-B-LH antibody in the antibody-enzyme (horseradish peroxidase) conjugate solution. The test sample is allowed to react simultaneously with the antibodies, resulting in LH molecules being sandwiched between the solid phase and enzyme linked antibodies. After 45 minutes incubation at room temperature, the wells are washed with water to remove unbound-labelled antibodies. A solution of TMB reagent is added and incubated for 20 minutes, resulting in the development of a blue colour. The colour development is stopped with the addition of stop solution, and the colour is changed to yellow and measured spectrophotometerically at450nm [8]. The average absorbance values $\left(\mathrm{A}_{450}\right)$ for each set of reference standards, control and samples were calculated. A standard curve constructed by plotting the mean absorbance obtained from each reference standard against its concentration in $\mathrm{mIU} / \mathrm{ml}$ on linear graph paper with absorbance values on the vertical or Y-axis and concentrations on the horse horizontal or X-axis. Using the mean absorbance value for each sample, the corresponding concentration of $\mathrm{LH}$ in $\mathrm{mlu} / \mathrm{ml}$ was determined from the standard curve. Reference Ranges for The Luteinizing Hormone was $1.6-15 \mathrm{miu} / \mathrm{ml}$

\section{Determination of Follicule Stimulating Hormone}

The level of FSH was determined using Enzyme Immunoassay test Kit produced by Biochek, Inc. The FSH quantitative test is based on a solid phase enzyme-linked immunosorbent assay (ELISA). The assay system utilizes a mouse monoclonal anti- $\alpha$-FSH anti-body for solid phase (microtiter wells) immobilization and another mouse monoclonal anti- $\beta$-FSH antibody in the anti-body enzyme (horseradish peroxidase) conjugate solution. The test sample is allowed to react simultaneously with the antibodies, resulting in FSH molecules being sandwiched between the solid phase and enzyme-linked antibodies. A solution of TMB Reagent is added and incubated at room temperature for 20 minutes, resulting in the development of a blue color. The color development is stopped with the addition of stop solution and the color is changed to yellow and measured spectrophotometrically at $450 \mathrm{~nm}$. The concentration of FSH is directly proportional to the color intensity of the test sample [9, 10 and 11]. The average absorbance values $\left(\mathrm{A}_{450}\right)$ for each set of reference standards, control and samples were calculated. A standard curve constructed by plotting the mean absorbance obtained from each reference standard against its concentration in $\mathrm{mIU} / \mathrm{ml}$ on linear graph paper with absorbance values on the vertical or $\mathrm{Y}$-axis and concentrations on the horse horizontal or X-axis. Using the mean absorbance value for each sample, the corresponding concentration of FSH in miu/ml was determined from the standard curve. Reference range for Follicule Stimulation Hormone $(\mathrm{FSH})=3.0-12 \mathrm{miu} / \mathrm{ml}$

\section{Results}

Tables 1 and 2 show the levels of LH and FSH statistically t-test, the p-value and Pearson Correlation. Figures 1 and 2 shows the mean concentrations of LH and FSH (in miu/ml) and SEM of control and study groups respectively.

Table 1: Mean value, standard deviation and standard error of mean of the study and control groups Group Statistics

\begin{tabular}{|l|l|l|l|l|l|}
\hline & Group & N & Mean & \pm Std. Error Mean & Std. Deviation \\
\hline \multirow{2}{*}{ LH $(\mathrm{miu} / \mathrm{ml})$} & Control & 30 & 9.080 & .7196 & 3.9417 \\
& Study & 30 & 22.580 & 2.7805 & 15.2293 \\
\hline \multirow{2}{*}{ FSH $(\mathrm{miu} / \mathrm{ml})$} & Control & 30 & 5.643 & .3125 & 1.7118 \\
& Study & 30 & 8.570 & 1.1492 & 6.2942 \\
\hline
\end{tabular}


Table 2: $\mathrm{t}-$ test, for the equality of Means in the Hormone Analyses Independent Samples Test

\begin{tabular}{|l|l|l|l|}
\hline \multirow{2}{*}{ Hormones } & \multicolumn{3}{l|}{ t-test for Equality of Means } \\
\cline { 2 - 4 } & t & Df & P-value \\
\hline Luteinizing $(\mathrm{miu} / \mathrm{ml})$ & -4.700 & 58 & .000 \\
Follicle Stimulating Hormone (miu/ml) & -2.458 & 58 & .017 \\
\hline
\end{tabular}

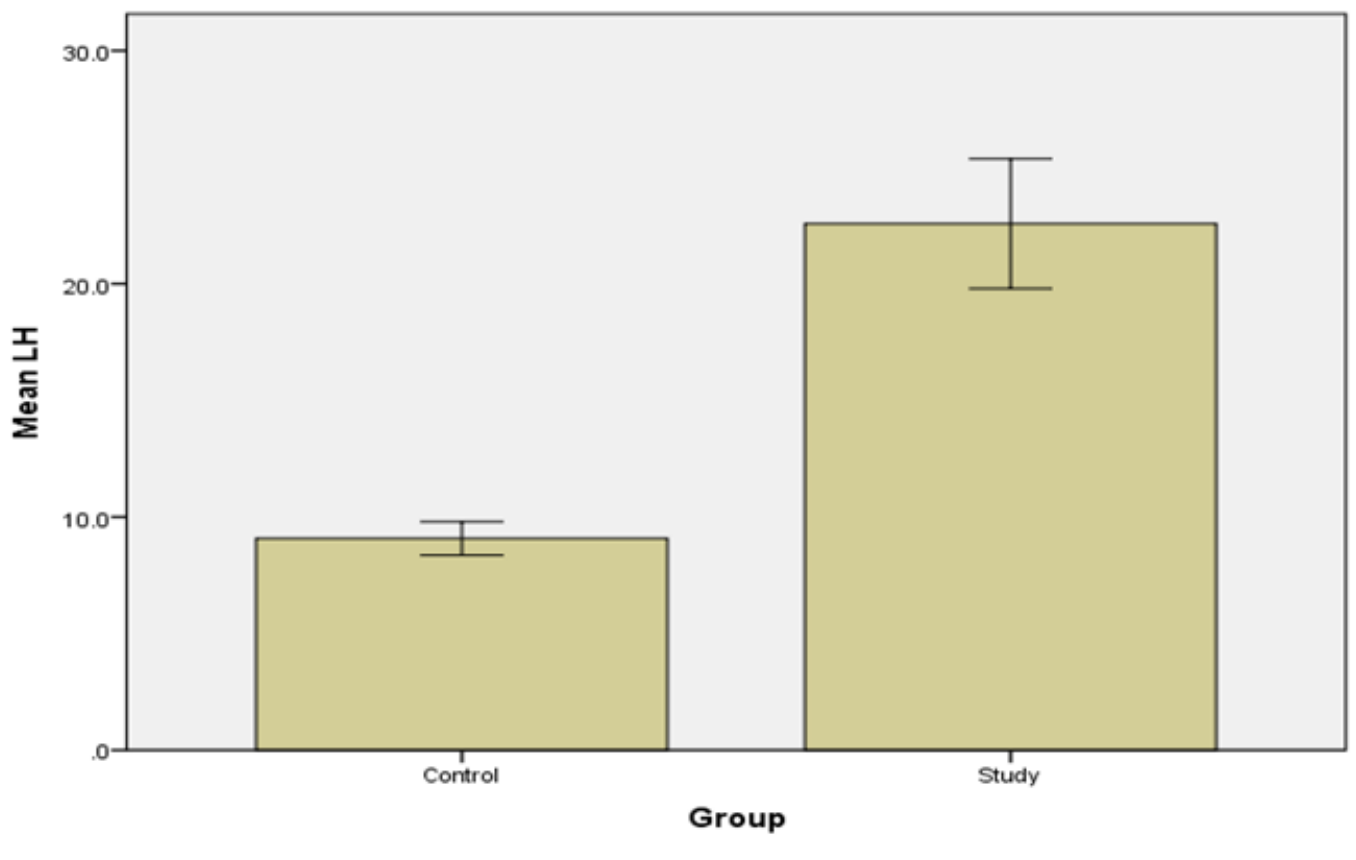

Error bars: +/ $1 \mathrm{SE}$

Fig.1: Mean concentration of LH (miu/ml) and SEM of control and study group

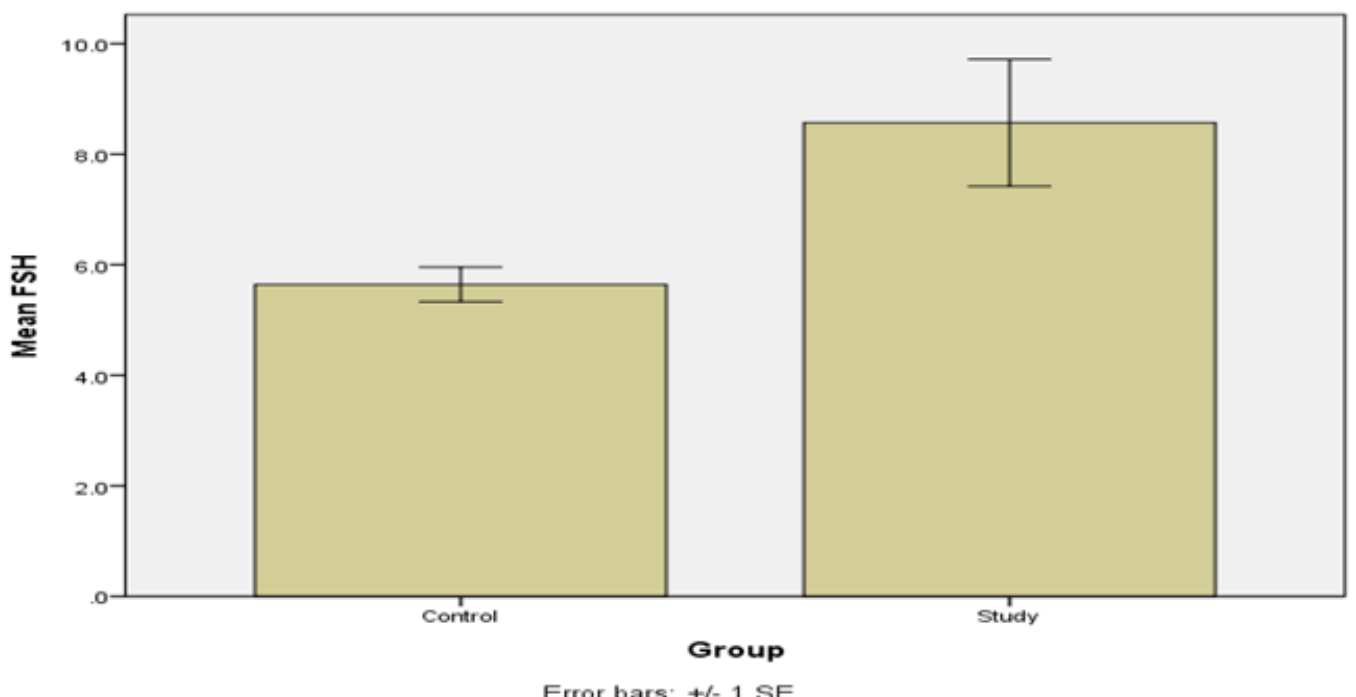

Fig 2: Mean concentration of FSH (miu/ml) and SEM of control and study group

\section{Discussion}

The mean concentration of $\mathrm{LH}$ was found to be $(22.58 \pm 2.781)$ in women with polycystic ovarian syndrome while in women free from polycystic ovarian syndrome was found to be $(9.080 \pm 0.720)$. $\mathrm{LH}$ in women with PCOS was significantly higher than in the control at $p<0.05$. This elevation of LH in the studied women confirms that PCOS leads to abnormally high secretion of LH.

The mean concentration of FSH $(8.570 \pm 1.149)$ of women with polycystic ovarian syndrome and the mean concentration women free from polycystic ovarian syndrome was found to be $(5.643 \pm 0.720)$. This study shows that there was elevated level of Follicle Stimulating hormone in women with polycystic ovarian 
syndrome compared to women free from polycystic ovarian syndrome. Follicle Stimulating hormone in women with PCOS was significantly higher than in the control at $\mathrm{p}<0.05$.

\section{Conclusion}

The result of the study showed there was a significant difference in the activity of the fertility hormones assayed between women with polycystic ovary syndrome and women free from polycystic ovary syndrome. The abnormal levels of these fertility hormones in polycystic ovary syndrome as the result shows have grave consequences. Polycystic ovary syndrome (PCOS) is the most common cause of anovulatory infertility. Its prevalence among of reproductive age as estimated is devastating, because it could lead to failed marriages, hyperandrogenism, amenorrhea (lack of menstruation) or oligomenorrhea acne, and risk of developing type 2 diabetes mellitus. Early diagnosis of PCOS is required and appropriate treatment given to balance the hormones and eliminate all the problems that comes with it.

\section{References}

[1]. Stein I.F. and Leventhal M.L. (1935) Amenorrhea associated with bilateral polycystic ovaries. Am J Obstet Gynecol 29:181

[2]. Legro R.S., Kunselman A.R. and Dodson W.C. (1999) Prevalence and predictors of risk for type 2 diabetes mellitus and impaired glucose tolerance in polycystic ovary syndrome: a prospective, controlled study in 254 affected women. J Clin Endocrinol Metab $84: 165-9$,

[3]. Goldzieher J.W. and Green J.A. (1962) The polycystic ovary. I. Clinical and histologic features. J Clin Endocrinol Metab 50:113116 ,

[4]. Falsetti L, Eleftheriou G. (1996) Hyperinsulinemia in the polycystic ovary syndrome: a clinical endocrine and echographic study in 240 patients. Gynaecol Endocrinol, 10: 319-26.

[5]. Banaszewska B., Spaczyński R.Z., Pelesz M and Pawelczyk L. (2003) Incidence of elevated LH/FSH ratio in polycystic ovary syndrome women with normo- and hyperinsulinemia, Annales Academiae Medicae Bialostocensis, Vol 48 pp 131-134

[6]. Franks S. (1989). Polycystic Ovary Syndrome: A Changing Perspective. Clinical Endocrinology (Oxf); 31:87-120.

[7]. Ugwu G. O, Iyoke C.A, Onah H.E, Mba S.G. (2013). Prevalence, Presentation and Management of Polycystic Ovary Syndrome in Enugu, South East Nigeria. Niger Journal of Medicine, www.ncbi.nlm.nih.gov pp 1-9

[8]. Knobil, E. (1980). The Neuroendocrine Control of the Menstrual Cycle, Rec. Progesterone. Hormone. Restrictions, 36:52-88; 1.

[9]. Rebar R. W., Erickson G.F. and Yen S.S. (1982); Idiopathic Premature Ovarian Failure: Clinical and Endocrine characteristics Fertil. Steril.Vol 37 p 35.

[10]. Abraham, G. E. Ed. (1981). Radioassay Systems in Clinic.Endocrinology. Marcel Dekker, Inc., New York pp 13: 12-34

[11]. Uotila, M., Ruoslahti, E. and Engvall, E. (1981). Two-site sandwich enzyme immunoassay with monoclonal antibodies to human alpha-fetoprotein, Journals of Immunology Methods, 42:11-15. 